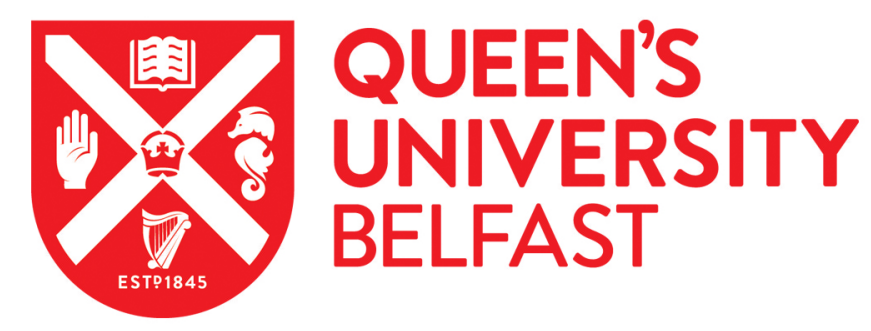

\title{
Clearance of intracellular Klebsiella pneumoniae infection using gentamicin-loaded nanoparticles
}

Jiang, L., Greene, M. K., Insua, J. L., Sa-Pessoa, J., Small, D. M., Smyth, P., McCann, A., Cogo, F., Bengoechea, J. A., Taggart, C. C., \& Scott, C. J. (2018). Clearance of intracellular Klebsiella pneumoniae infection using gentamicin-loaded nanoparticles. Journal of Controlled Release, 279, 316.

https://doi.org/10.1016/j.jconrel.2018.04.040

Published in:

Journal of Controlled Release

Document Version:

Peer reviewed version

Queen's University Belfast - Research Portal:

Link to publication record in Queen's University Belfast Research Portal

Publisher rights

(C) 2018 Elsevier.

This manuscript is distributed under a Creative Commons Attribution-NonCommercial-NoDerivs License

(https://creativecommons.org/licenses/by-nc-nd/4.0/), which permits distribution and reproduction for non-commercial purposes, provided the author and source are cited.

\section{General rights}

Copyright for the publications made accessible via the Queen's University Belfast Research Portal is retained by the author(s) and / or other copyright owners and it is a condition of accessing these publications that users recognise and abide by the legal requirements associated with these rights.

Take down policy

The Research Portal is Queen's institutional repository that provides access to Queen's research output. Every effort has been made to ensure that content in the Research Portal does not infringe any person's rights, or applicable UK laws. If you discover content in the Research Portal that you believe breaches copyright or violates any law, please contact openaccess@qub.ac.uk. 


\section{Accepted Manuscript}

Clearance of intracellular Klebsiella pneumoniae infection using gentamicin-loaded nanoparticles

Lai Jiang, Michelle K. Greene, Jose Luis Insua, Joana Sa Pessoa, Donna M. Small, Peter Smyth, Aidan McCann, Francesco Cogo, Jose A. Bengoechea, Clifford C. Taggart, Christopher J. Scott

PII: S0168-3659(18)30224-4

DOI: doi:10.1016/j.jconrel.2018.04.040

Reference: COREL 9267

To appear in: Journal of Controlled Release

Received date:

8 January 2018

Revised date: 16 April 2018

Accepted date: 20 April 2018

Please cite this article as: Lai Jiang, Michelle K. Greene, Jose Luis Insua, Joana Sa Pessoa, Donna M. Small, Peter Smyth, Aidan McCann, Francesco Cogo, Jose A. Bengoechea, Clifford C. Taggart, Christopher J. Scott, Clearance of intracellular Klebsiella pneumoniae infection using gentamicin-loaded nanoparticles. The address for the corresponding author was captured as affiliation for all authors. Please check if appropriate. Corel(2018), doi:10.1016/j.jconrel.2018.04.040

This is a PDF file of an unedited manuscript that has been accepted for publication. As a service to our customers we are providing this early version of the manuscript. The manuscript will undergo copyediting, typesetting, and review of the resulting proof before it is published in its final form. Please note that during the production process errors may be discovered which could affect the content, and all legal disclaimers that apply to the journal pertain. 


\section{Clearance of intracellular Klebsiella pneumoniae infection using gentamicin-loaded nanoparticles}

Lai Jiang ${ }^{a}$, Michelle K. Greene ${ }^{c}$, Jose Luis Insua ${ }^{a}$, Joana Sa Pessoa ${ }^{a}$, Donna M. Small ${ }^{\text {a }}$, Peter Smyth $^{\mathrm{c}}$, Aidan McCann ${ }^{\mathrm{c}}$, Francesco Cogo ${ }^{\mathrm{c}}$, Jose A. Bengoechea ${ }^{\mathrm{a}}$, Clifford C. Taggart $^{\mathrm{a}}$ and Christopher J. Scott ${ }^{\mathrm{b}, *}$.

${ }^{a}$ Centre for Experimental Medicine, School of Medicine, Dentistry and Biomedical Sciences, Queen's University Belfast, 97 Lisburn Road, Belfast, BT9 7BL, Northern Ireland, UK

${ }^{\mathrm{b}}$ Centre for Cancer Research and Cell Biology, School of Medicine, Dentistry and Biomedical Sciences, Queen's University Belfast, 97 Lisburn Road, Belfast, BT9 7BL, Northern Ireland, UK

'School of Pharmacy, Queen's University Belfast, 97 Lisburn Road, Belfast, BT9 7BL, Northern Ireland, UK

*Corresponding author. E-mail address: c.scott@qub.ac.uk (C.J. Scott).

Tel: $+44(0) 2890972350$ 


\section{Abstract}

Klebsiella pneumoniae is a foremost gram-negative pathogen that can induce life-threatening nosocomial pulmonary infections. Although it can be phagocytosed successfully by lung resident macrophages, this pathogen remains viable within vacuolar compartments, resulting in chronic infection and limiting therapeutic treatment with antibiotics. In this study, we aimed to generate and evaluate a cell-penetrant antibiotic poly(lactide-co-glycolide) (PLGA)-based formulation that could successfully treat intracellular K. pneumoniae infection. Screening of formulation conditions allowed the generation of high drug entrapment nanoparticles through a water-in-oil-in-water approach. We demonstrated the therapeutic usefulness of these gentamicin-loaded nanoparticles (GNPs), showing their ability to improve survival and provide extended prophylactic protection towards $K$. pneumoniae using a Galleria mellonella infection model. We subsequently showed that the GNPs could be phagocytosed by $K$. pneumoniae infected macrophages, and significantly reduce the viability of the intracellular bacteria without further stimulation of pro-inflammatory or pro-apoptotic effects on the macrophages. Taken together, these results clearly show the potential to use antibiotic loaded NPs to treat intracellular $K$. pneumoniae infection, reducing bacterial viability without concomitant stimulation of inflammatory or pyroptotic pathways in the treated cells.

Keywords: Gentamicin, PLGA, nanoparticles, Klebsiella pneumoniae, intracellular infection, macrophage, inflammation, pyroptosis 


\section{Introduction}

Klebsiella pneumoniae is identified by the World Health Organisation to be of major concern for human health [1]. It is considered one of the most important gram-negative pathogens in nosocomial infection, frequently inducing severe pulmonary infections, particularly in elderly patients with impaired immunological defenses [2,3]. However, it can also infect other parts of the body including the urinary tract, lower biliary tract and surgical wound sites [4-6]. As with other bacterial pathogens, continual use of key therapies is driving the growing prevalence of serious antibiotic resistant strains, leading to increased concerns about present and future treatment options [7].

Recently, it has been reported that $K$. pneumoniae survives intracellularly after phagocytosis into macrophages by limiting the fusion of lysosomes with the Klebsiella containing vacuole (KCV), creating an intracellular reservoir of infection [8]. Clinical treatment of this intracellular pool of infection is challenging; for example, aminoglycosides, which can successfully treat extracellular $K$. pneumoniae infections, have poor cellular penetration, unsatisfactory subcellular distribution and consequently have sub-optimal activity towards intracellular infection [9-13]. Taken together, it is clear that both new drugs and novel delivery strategies are needed to treat this persistent and frequently lethal intracellular pathogen.

In this current study, we have examined the ability to enhance the delivery of a clinically relevant antibiotic into $K$. pneumoniae infected macrophages using an alternative nanoformulation approach. Nanoparticle formulations are growing in popularity as potential solutions to improve the pharmacokinetics of active pharmaceutical ingredients (API), 
alleviate systemic toxicities through drug encapsulation, and also provide controlled or sustained release properties to extend therapeutic windows [14-18].

Nanoparticle drug systems for the treatment of $K$. pneumoniae have been investigated previously. These include the application of metal nanoparticles such as gold or silver which has inherent anti-microbial properties [19]. Antibiotic loaded nanoparticle systems have also been examined including ceftazidime-loaded liposomes or gentamicin-loaded chitosan/fucoidan nanoparticles to enhance pulmonary delivery of the antibiotics $[20,15]$. However to date, studies have not addressed the specific treatment of the intracellular reservoir of infection. Herein we have aimed to develop a polymeric based nanoparticle with high drug loading that would be taken up into infected macrophages by phagocytosis to deliver the antibiotic at the site of intracellular infection; providing passive targeting of the antibiotic into the intracellular compartments of the cells to elicit enhanced antimicrobial effects. We demonstrate the potential effectiveness of this approach for the delivery of gentamicin towards intracellular K. pneumoniae infection.

\section{Materials and Methods}

\subsection{Materials}

All general chemicals and reagents were supplied by Sigma-Aldrich UK, unless otherwise specified. Gentamicin sulphate was purchased from Discovery Fine Chemicals, UK. Water used for formulations was double distilled, HPLC grade water.

\subsection{Formulation of Gentamicin-loaded PLGA Nanoparticles (GNPs)}


A water-in-oil-in-water (w/o/w) formulation strategy was adopted for the development of the gentamicin-loaded nanoparticles. Briefly, gentamicin was dissolved in $0.5 \mathrm{ml}$ of $1 \%$ aqueous polyvinyl alcohol (PVA) solution (w/v, in $0.95 \%$ MES buffer, $\mathrm{pH} 7$ ), followed by drop-wise addition of $2 \mathrm{ml}$ of dichloromethane (DCM) containing $20 \mathrm{mg}$ of PLGA (LG 50:50, 502H, 7000-17000 Da) via a 25G needle. For rhodamine- labelled nanoparticles (RNPs), $10 \%$ (w/w) rhodamine-B conjugated PLGA (AV011, PolySciTech, Akina, USA) was blended with PLGA $(502 \mathrm{H})$. The primary emulsion was obtained by sonication at 60 watts for 12 cycles in pulse mode (3 sec on, $2 \mathrm{sec}$ off) while stirring at $1000 \mathrm{rpm}$ (MS-53M multiposition stirrer, JEIO TECH, Korea). Subsequently, $10 \mathrm{ml}$ of aqueous PVA solution was poured into the primary emulsion and sonicated for another 18 pulse sonication cycles as before. The nanoparticle suspension was stirred for 4 hours to evaporate DCM and then washed twice by centrifugation and resuspension cycles (at $20000 \mathrm{~g}, 20 \mathrm{~min}, 4^{\circ} \mathrm{C}$ ) in phosphate buffered saline (PBS). Various modifications to this formulation approach were assessed during process optimization including varying the concentrations of PLGA and PVA, different aqueous phase in the emulsion step and the $\mathrm{pH}$ of external aqueous phase as discussed in the results section.

\subsection{Characterisation of GNPs}

Triplicate NP batches were diluted in PBS and characterised by Zetasizer (Nano ZS, Malvern Instruments Ltd., UK) measurements, recording mean particle size $\left(\mathrm{Z}_{\mathrm{ave}}\right)$, polydispersity index (PDI) and zeta potential. For Scanning Electron Microscopy (SEM), small droplets (10 $\mu \mathrm{l}, 3 \mathrm{mg} / \mathrm{ml}$ ) of the final formulation of GNP and associated blank nanoparticle (BNP) controls were dried and sputter-coated with gold on aluminum stubs and visualised (Jeol 6500 field emission gun, Japan). 


\subsection{Quantification of Drug Loading in GNPs}

Drug loading was calculated by analysis of residual gentamicin in the supernatants obtained after nanoparticle precipitation. Calibration curves were prepared using known concentrations of gentamicin dissolved in the supernatant of BNPs. In this way, any interference was accounted for at each concentration. Based on a protocol of aminoglycoside detection [21], $50 \mu 1$ of gentamicin solution was added into a 96-well plate, followed by addition of $50 \mu \mathrm{l}$ of a mixture of reagent A ( $1 \mathrm{ml}$ of $80 \mathrm{mg} / \mathrm{ml} \mathrm{O}$-phthaldialdehyde in $95 \%$ ethanol) and reagent B (200 $\mu 1$ of $0.4 \mathrm{M}$ boric acid pH 9.7, $400 \mu \mathrm{l}$ of 2-Mercaptoethanol and $200 \mu 1$ of diethyl ether). The fluorescence was measured at 360/460 nm using a fluorometer (FLUO star Optima, BMG Labtech).

The release of gentamicin from the GNPs was assessed using $2 \mathrm{ml}$ of GNPs $(10 \mathrm{mg} / \mathrm{ml})$ in PBS buffer (at either pH 5 or $\mathrm{pH} 7$ ), which was injected into a Slide-A-Lyzer ${ }^{\circledR}$ Dialysis Cassette 7000 MW (Thermo Scientific, UK). For comparison to free gentamicin diffusion, 2 $\mathrm{ml}$ of gentamicin sulfate $(2 \mathrm{mg} / \mathrm{ml}$ ) in PBS buffer (at either $\mathrm{pH} 5$ or $\mathrm{pH} 7$ ) was injected into separate cassettes. The cassettes were then placed into a $30 \mathrm{ml}$ reservoir of PBS buffer (at either $\mathrm{pH} 5$ or $\mathrm{pH} 7$ ) in an incubator at $37{ }^{\circ} \mathrm{C}$, with shaking at $120 \mathrm{rpm}$ (SI50 Orbital Incubator, Stuart Scientific, UK). At pre-determined time points, $1 \mathrm{ml}$ samples were removed from the reservoir and replaced with $1 \mathrm{ml}$ fresh PBS buffer. The gentamicin content in samples was quantified by comparison to standards containing known amounts of gentamicin in PBS buffer (at either $\mathrm{pH} 5$ or $\mathrm{pH} 7$ ).

\subsection{Bacterial Strains and Growth Conditions}


K. pneumoniae (stain 43816) was cultured on LB (Luria-Bertani) agar plates for 18 hours at $37^{\circ} \mathrm{C}$. LB broth was inoculated with one bacteria colony and incubated overnight at $37^{\circ} \mathrm{C}$ while shaking at $180 \mathrm{rpm}$ (SI50 Orbital Incubator, Stuart Scientific, UK). The bacteria were harvested by centrifugation (at $2500 \mathrm{~g}, 20 \mathrm{~min}, 24^{\circ} \mathrm{C}$ ), and then diluted to a defined optical density $\left(\mathrm{A}_{600}\right)$. The colony forming units $(\mathrm{CFU})$ were determined by plating serial bacterial dilutions prepared in PBS onto agar plates and visible colonies were counted following overnight incubation at $37^{\circ} \mathrm{C}$.

\section{6 in vitro Antimicrobial Activity}

For planktonic $K$. pneumoniae assay, broth microdilution tests were performed to determine the minimum inhibitory concentration (MIC) of GNPs against $K$. pneumoniae. After overnight growth and $2.5 \mathrm{hrs}$ refreshing incubation, the $K$. pneumoniae suspension was adjusted to an optical density of $1.0\left(\mathrm{~A}_{600}\right)$ and diluted in LB broth to give a starting inoculum of $5000 \mathrm{CFU} / \mathrm{ml}$. A $100 \mu \mathrm{l}$ volume of serially diluted free gentamicin, GNPs and BNPs in LB broth were added to a 96-well plate containing $100 \mu \mathrm{l}$ of diluted $K$. pneumoniae. Concentrations of both free and nanoencapsulated gentamicin were equalised in all studies. Polymer concentrations were also equalised when comparing BNPs and GNPs. The plates were incubated overnight at $37^{\circ} \mathrm{C}$ with shaking at $120 \mathrm{rpm} . \mathrm{A}_{600}$ was measured and background absorbance from the negatively controlled wells (the absorbance of LB broth or nanoparticles only) was subtracted from all wells before analysis. The lowest concentration at which mean $\mathrm{A}_{600}$ was zero was designated the MIC. The minimum bactericidal concentration (MBC) was determined by the absence of growth on LB agar plates of $100 \mu \mathrm{L}$ mixtures from each challenged well after stipulated incubation times. 
Biofilm susceptibility assays were performed using the MBEC $^{\circledR}$ Assay (Innovotech, Edmonton, Alberta, Canada). K. pneumoniae (150 $\mu \mathrm{L} /$ well, $5 \times 10^{5} \mathrm{CFU} / \mathrm{mL}$ in LB broth) was added to an MBEC plate and incubated for 24 hours $\left(37^{\circ} \mathrm{C}, 120 \mathrm{rpm}\right)$ to allow biofilm formation on the pegs. Biofilms pegs were immersed twice for 2 minutes in sterile PBS to remove loosely adhered bacteria. Then the pegs were challenged with a range of concentrations of either free gentamicin $(0-400 \mu \mathrm{g} / \mathrm{mL})$ or nanoparticle formulations in 200 $\mu \mathrm{L} \mathrm{LB}$ broth for another 24 hours $\left(37^{\circ} \mathrm{C}, 120 \mathrm{rpm}\right)$. The challenge plate was then measured for biofilm derived MIC, and the lid pegs were rinsed again and then placed in a new plate containing fresh LB broth (recovery plate). Biofilms were disrupted by sonication for 10 minutes, and then incubated for a further 24 hours. The minimum biofilm eradication concentration (MBEC) was designated as the lowest concentration in the recovery plate at which there was no observable growth.

\section{7 in vivo Antimicrobial Activity}

The in vivo antimicrobial activity of GNPs was investigated using the in vivo Galleria Mellonella (www.livefoodsdirect.co.uk, UK) model. In a post-infection study, $\mathrm{LD}_{50} \mathrm{~K}$. pneumoniae infected larvae were each treated with NP formulations or free drug $(3.6 \mu \mathrm{g}$ gentamicin equivalents) and survival percentage was monitored in the following 96 hours. In a pre-treatment study, the same dosages of NPs and free gentamicin were given $0,24,48,72$, 96 and 120 hours prior to $\mathrm{LD}_{50}$ infection, and then survival percentages were monitored in the next 120 hours. For each experiment, 10 larvae per group were studied and $20 \mu 1$ of injections were administered via a $29 \mathrm{G}$ needle into the last pro-legs. Hemocyte quantification was determined from $K$. pneumoniae infected larvae at 1, 5, 8, 12, and $24 \mathrm{hrs}$ 
post-infection. Briefly, hemolymph samples from three larvae were pooled in a micro-centrifuge tube containing $10 \mu \mathrm{l}$ of N-phenylthiourea (Sigma). Then $50 \mu 1$ of trypan blue $(0.02 \% \mathrm{v} / \mathrm{v}$ in PBS) was added to the samples prior to enumeration by hemocytometer after 10 minutes. Each sample was analyzed in triplicate. In a further study the residual bacterial load from larvae was determined by isolation of the hemolymph of 10 larvae from treatment groups at $8 \mathrm{hrs}$ post-infection. The hemolymph were pooled as before in PBS and serial dilutions of the suspensions were plated on LB agar and colonies were counted after incubation at $37^{\circ} \mathrm{C}$ for $24 \mathrm{~h}$.

\subsection{Histopathological analysis}

Histopathological analysis of the infected and treated larvae was performed through larvae fixation in $10 \%$ formalin for 3 days at room temperature, before processing with a Leica TP1020 processor, embedded and sectioned with Leica RM2235 microtome. The sections were de-paraffinised in three changes of xylene (Sigma, UK) for $15 \mathrm{~min}$ each. The tissues were then hydrated over an ethanol-to-water (95-70\% ethanol v/v) gradient, for $5 \mathrm{~min}$ each. Thereafter, the sections were washed in water for $2 \mathrm{~min}$ and transferred into pre-filtered acidified Harris haematoxylin stain (Surgipath Leica Biosystems, UK) for 5 min. Then the sections were washed with water for another $30 \mathrm{sec}$ and cleared with acid alcohol for $15 \mathrm{sec}$. After a further wash in water, the sections were immersed in aqueous eosin stain (Surgipath Leica Biosystems, UK) for $5 \mathrm{~min}$. Then the sections were dehydrated over a water-to-ethanol gradient $(70-100 \%$ ethanol v/v), for 1 min each. Following submersion in xylene for 5 min, one drop of DPX mountant was applied to each section and coverslips were positioned. The slides were incubated overnight at room temperature and followed checked by a DM5500B microscope (Leica Microsystems, Germany). 


\subsection{Confocal Microscopy}

For the localization of $K$. pneumoniae and NPs in Galleria mellonella, GFP-tagged $K$. pneumoniae 43816 and RNPs were injected into larvae and incubated for 5 hrs. Section samples were prepared as described above. After a dewax step, the sections were covered by mounting medium with DAPI (Vector Laboratories, USA).

For the subcellular localization of $K$. pneumoniae and NPs in in vitro macrophage studies, murine alveolar macrophage MH-S (ATCC CRL-2019) cell line were seeded on a 24-well plate containing individual $12 \mathrm{~mm}$ circular coverslips. After infection and treatments, the coverslip was washed with PBS twice and fixed with 4\% PFA for $20 \mathrm{~min}$ in the dark. Staining was carried out in $10 \%$ horse serum and $0.1 \%$ saponin in PBS. Coverslips were washed twice in PBS and incubated for 1 hour with rat anti-Lamp-1 antibody (1D4B, Santa Cruz Biotechnology Inc., Germany). Then the coverslips were washed again and incubated for 45 min with PBS containing 10\% horse serum, Hoechst 33342 (Invitrogen, UK) and donkey anti-rat conjugated to Cascade blue secondary antibody (Jackson ImmunoResearch Inc., USA). Coverslips were washed three times in PBS and once in distilled water before mounting onto glass slides using Prolong Gold anti-fade mounting gel (Invitrogen, UK).

\subsection{Assessment of Cytotoxic ity}

For assessment of formulation toxicity, MH-S cells were seeded at $4 \times 10^{4}$ per well in a 96-well white plate and treated with various concentrations of GNPs and BNPs. After treatments, the media in each well was carefully replaced by $100 \mu$ lof fresh media and $100 \mu 1$ 
of CellTiter Glo ${ }^{\circledR}$ reagent (Promega, UK) was then added into each well. The plates were placed on a shaker to induce cell lysis for 2 minutes and transferred to darkness for 10 minutes to stabilize the luminescent signal at room temperature. A spectrophotometer (Synergy 2 Multi-Mode Reader, BioTek Instruments, USA) was used to measure luminescence and cell viability was calculated as a relative percentage compared with untreated $\mathrm{MH}-\mathrm{S}$ cells.

\subsection{GNPs Treatment of Infection in an Intracellular Co-Culture Model}

For the intracellular co-culture model, MH-S and human monocytic THP-1 (ATCC TIB-201) cells were separately seeded in RPMI-1640 medium (10\% FCS, without antibiotics) at a density of $3 \times 10^{5}$ per well in a 24 -well plate 18 hours before experiments. Infections were performed as previously described with minor modifications. Briefly, bacteria were grown in LB broth overnight, harvested by centrifugation $\left(2500 \mathrm{~g}, 20 \mathrm{~min}, 25^{\circ} \mathrm{C}\right)$, washed once in PBS and adjusted to an optical density of $1.0\left(\mathrm{~A}_{600}\right)$, equating to approximately $5 \times 10^{8} \mathrm{CFU} / \mathrm{mL}$. Cells were infected with $100 \mu \mathrm{l}$ of bacterial suspension to give a multiplicity of infection (MOI) of 100. The plate was centrifuged at $200 \mathrm{~g}$ for $5 \mathrm{~min}$ to synchronize the infection and then incubated at $37^{\circ} \mathrm{C}$ for 1 hour. After contact, the cells were washed twice with PBS and incubated for another 45 min with fresh RPMI-1640 (10\% FCS, $100 \mu \mathrm{g} / \mathrm{ml}$ of gentamicin). The cells were then washed in PBS and incubated with fresh RPMI-1640 (10\% FCS, 30 $\mu \mathrm{g} / \mathrm{ml}$ of gentamicin) containing various concentrations of GNPs and BNPs. For the untreated group (free gentamicin group), the cells were incubated in RPMI-1640 (10\% FCS, $30 \mu \mathrm{g} / \mathrm{ml}$ of gentamicin) only. The inclusion of free gentamicin in the media is a standard procedure to eliminate extracellular or cell surface bound bacteria which could contaminate determination of intracellular infection [8]. After treatments, the cells were washed twice 
with PBS and lysed with $300 \mu$ of $0.1 \%$ saponin in PBS for $10 \mathrm{~min}$ at room temperature. Serial dilutions in PBS were plated on agar plates to quantify the number of intracellular bacteria after overnight incubation. The intracellular bacterial load is represented as CFU/ well.

\subsection{Caspase Activity Assay}

Treated/infected cells were washed with PBS and resuspended in $100 \mu 1$ of lysis buffer (25 mM HEPES, $100 \mathrm{mM} \mathrm{NaCl}, 2$ mM EDTA, $0.1 \%$ CHAPS, 10\% sucrose, $\mathrm{pH}$ 7.4) before incubation on ice for 30 mins. Samples were periodically vortexed and at the end of the incubation, sonicated for 10 secs on ice to complete lysis. Once completed, the lysates were clarified by centrifugation at $16000 \mathrm{~g}$ for $20 \mathrm{mins}$ at $4{ }^{\circ} \mathrm{C}$ and protein content was quantified by BCA assay (Pierce ${ }^{\circledR}$ BCA protein assay kit, Thermo, UK). Clarified lysate samples $(50 \mu \mathrm{g}$ protein) were added in triplicate to a black 96-well plate in caspase activity buffer (50 $\mathrm{mM}$ HEPES, $1 \mathrm{mM}$ EDTA, $1 \%$ CHAPS, $10 \%$ sucrose, $10 \mathrm{mM}$ DTT, pH 7.40) to a final volume of $200 \mu \mathrm{l}$ per well. Caspase 1 or caspase 3 activity was measured by addition of Ac-YVAD-AMC (ALX-260-024, Enzo Life Science, UK) or Ac-DEVD-AMC (ALX-260-031, Enzo Life Science, UK) (final concentration, $50 \mu \mathrm{M}$ ), and measurement of increase in fluorescence over 60 mins was recorded.

For visualisation of cytoplasmic caspase-1 activity in infected and treated macrophages, FAM-FLICA $^{\circledR}$ caspase-1 probe (Immuno Chemistry Technologies, USA) was incubated (prepared and diluted as per manufacturer's instructions) with seeded and treated macrophages prepared as above for $1 \mathrm{~h}$. Then the media was removed and cells were washed with PBS for 3 times. The cells were fixed and stained with Hoechst 33342. Confocal 
microscopy was carried out with a Leica TCS SP8 confocal microscope (Leica Microsystems Ltd., UK) and images were taken with a Leica DFC350FX monochrome camera.

\subsection{Statistical Analysis}

Results were analysed with GraphPad Prism, version 6.0c, GraphPad Software (San Diego, USA). G. mellonella survival shown as Kaplan-Meier plots and analysis was performed using the log rank (Mantel-Cox) test for significance. As detailed in figure legends, $\mathrm{t}$-tests and one-way ANOVA analyses were conducted. Statistical significance critical values were defined as $* \mathrm{P}<0.05, * * \mathrm{P}<0.01, * * * \mathrm{P}<0.001$ and $* * * * \mathrm{P}<0.0001$.

\section{Results and Discussion}

\subsection{Enhanced Formulation of Gentamicin-loaded Nanoparticles}

Gentamicin is a broad-spectrum aminoglycoside antibiotic which is widely used against $K$. pneumoniae. However, it is poorly cell permeable, which limits its clinical effectiveness to treat infections caused by intracellular facultative pathogens. Notably, there is a growing body of evidence demonstrating that $K$. pneumoniae survives inside macrophages in vitro and in vivo [22], making it es sential to target this intracellular population to clear infection. In this report, we demonstrate the utility of a nanoparticle-based antibiotic delivery system in achieving this goal.

We have previously explored the development of alginate/chitosan and PLGA nanocarriers for the formulation of aminoglycoside antibiotics for controlled release purposes [23,24]. 
With respect to PLGA-based formulations we explored an evaporation approach to generate particles encapsulating some $22 \mu \mathrm{g}$ gentamicin per mg PLGA, bettering previous reports of 6-10 $\mu \mathrm{g} / \mathrm{mg}$ PLGA [25]. However, for this current work we re-evaluated our formulation to further enhance drug loading. A screen of formulation parameters including polymer and surfactant concentrations, employment of surfactant-containing aqueous phases in both emulsification steps and $\mathrm{pH}$ of the aqueous phase was examined (supplementary Figure 1). Through this approach, we determined that the use of a water-in-oil-in-water formulation process, and the presence of PVA surfactant in the second aqueous partition at neutral $\mathrm{pH}$ produced the maximum drug loading (schematic Figure 1), generating GNPs with up to 135 $\mu \mathrm{g}$ drug encapsulation per mg PLGA. Physical analysis of GNPs produced by this approach using Dynamic Light Scattering (DLS) confirmed their diameter as $227 \mathrm{~nm}$, with monodisperse nature with a PDI of 0.162 and a zeta potential of $-1.67 \mathrm{mV}$, which was further confirmed by SEM (Figure 2).

\subsection{Assessment of in vitro Antimicrobial Activity of Gentamicin-loaded Nanoparticles}

The biological activity of the GNPs was assessed in comparison to free drug at identical concentrations against planktonic K. pneumoniae (strain 43816) cultures in overnight incubations. The MICs of free gentamicin and GNPs were determined as $1.09 \mu \mathrm{g} / \mathrm{ml}$ and $10.94 \mu \mathrm{g} / \mathrm{ml}$ respectively (Figure 3A). Analysis of corresponding MBCs were determined as $1.09 \mu \mathrm{g} / \mathrm{ml}$ for the free drug and $10.94 \mu \mathrm{g} / \mathrm{ml}$ for the GNPs (supplementary Table 1 ). As expected, although the GNPs exhibited antimicrobial effects, these were reduced in comparison to equivalent concentrations of the free drug. It was postulated that this was a consequence of the encapsulation of the drug in the GNPs, thus preventing its immediate exposure to the bacteria. Therefore, we conducted incubations with the bacteria over a time 
course of up to $120 \mathrm{hrs}$, observing an enhancement of MBC for the GNP to $5.47 \mu \mathrm{g} / \mathrm{ml}$ at 96 and 120 hrs timepoints (whereas the free gentamicin MBC did not change), substantiating this hypothesis (supplementary Table 1). This was further confirmed by analysis of the drug release from the GNPs at $\mathrm{pH} 7.4$ which showed a controlled release profile where at $120 \mathrm{hrs}$ only $33 \%$ of the drug had been released under these experimental conditions (Figure 3B). Given that the overall strategy of the study was to examine the capability of the se GNP to deliver their antibiotic payload intracellularly within $\mathrm{KCVs}$, we also examined their release profile at $\mathrm{pH} 5.5$, more representative of late endosomal lumens. Here an accelerated release was observed (Figure 3B), where at $120 \mathrm{hrs}$ over $80 \%$ of the drug was released, highlighting the potential for this formulation to provided 'triggered' drug release once taken up by infected cells.

K. pneumoniae are known to be capable of generating biofilms [26,27], and these bacteria are more resistant to antibiotics including gentamicin [28,29]. First, the growth of biofilm-derived planktonic bacteria was examined. The biofilm-derived planktonic bacteria had increased tolerance to gentamicin as expected [27], where the MICs of free gentamicin and GNPs were measured at $25 \mu \mathrm{g} / \mathrm{ml}$ and $200 \mu \mathrm{g} / \mathrm{ml}$ (Figure 3C). Next, we analysed the ability of the GNPs and free drug control to inhibit growth of $K$. pneumoniae in $24 \mathrm{hrs}$ MBEC plate preformed peg biofilms. Following $24 \mathrm{hrs}$ antibiotic treatments, recovered bacteria were propagated establishing MBECs of free gentamicin and GNPs at $100 \mu \mathrm{g} / \mathrm{ml}$ and $400 \mu \mathrm{g} / \mathrm{ml}$, respectively (Figure 3D). Although the anti-biofilm effect of GNPs was reduced in comparison to free drug, these findings are in agreement with previous studies showing similar activity of antibiotics released from PLGA NPs in vitro [30].

3.3 Gentamicin-loaded NPs provide longer window of protection against $K$. pneumoniae in vivo 
Given the fact that a simple in vitro antimicrobial evaluation cannot show the potential of the GNPs, we employed the Galleria mellonella larvae in vivo model to further assess their antimicrobial activity towards $K$. pneumoniae infection. The G. mellonella model is widely used for antibiotic susceptibility and pharmacokinetic investigations and has been shown to have a positive correlation with mammalian models in determining virulence against gram-negative bacteria [31-33]. In agreement with published results, we established an $\mathrm{LD}_{50}$ of infection at $10^{4} \mathrm{CFU} /$ larvae (Figure 4A) [34]. Next, in an initial treatment study, larvae where challenged with $1 \times 10^{4}$ Klebsiella bacteria, and then free gentamicin solution (3.6 $\mu \mathrm{g} /$ larvae), GNPs (40 $\mu \mathrm{g} /$ larvae, at equivalent drug concentration), as well as non-drug loaded NPs or PBS $(10 \mu \mathrm{l})$ sham treatment controls. The analysis of larvae survival demonstrated that in the presence of PBS or non-drug loaded NPs as sham treatments, the larvae succumbed to the infection by $96 \mathrm{~h}$ (Figure 4B). However, when treated with either free drug or GNPs, survival was significantly enhanced. Importantly, these results highlighted that the nanoparticle formulation was as effective as the free drug in this in vivo model of infection. Furthermore, these results also highlighted the tolerance of the larvae to both the BNPs and GNPs, providing confidence in their potential biocompatibility. This suggests that in a more complex physiological microenvironment, similar levels of drug are exposed to the infection whether from free or NP formulation.

To further understand how the GNPs protect larvae survival from $K$. pneumoniae infection, we analysed the distribution of the infection and GNPs in the larvae. After infection and treatment with RNP, we were able to discern by fluorescence microscopy that the GFP-labelled K. pneumoniae and nanoparticles were both located within the hemocyte-rich fat body (FB) (Supplementary Figure 2). 
Histochemical analysis of the tissue from sectioned larvae then allowed us to observe the $K$. pneumoniae infected sites, which in non-drug treated larvae, became progressively melanised with time (black arrows, Supplementary Figure 3). This is consistent with hemocyte phagocytosis of foreign bodies and subsequent nodulization [35]. We also quantified hemocytes and bacterial counts from these larvae, establishing that infection significantly reduced hamocyte numbers (Figure 4C) and that bacteria where able to survive $8 \mathrm{~h}$ post infection (Figure 4D), in agreement to our previous work [34]. However, it was also clear that the gentamicin treatment (both in free or NP formulation) was able to prevent both tissue damage (supplementary Figure 3) and reduction in hemocyte numbers (Figure 4C), whilst concomitantly ablating residual bacteria viability (Figure 4D). This is in agreement with a recent study in G. mellonella showing that antibiotic treatment of candida albicans could reduce tissue damage in the larvae [36].

We hypothesized that the established controlled release properties of the GNPs may provide an extended protective window against subsequent $K$. pneumoniae infection in Galleria larvae. Larvae were treated prophylactically with either free drug or GNPs up to five days prior to bacterial challenge, and survival monitored for a subsequent five days (Figure 5). These experiments revealed that whilst a $24 \mathrm{hrs}$ pretreatment of both free and NPs entrapped gentamicin elicited no significant differences in survival to subsequent infection, it was clear that with both 48 and 72 hrs pretreatments, the GNP provided significantly enhanced protection. These results are consistent with the controlled release effect of the formulation providing an extended protective window against infection. However, at longer 96 and 120 hrs timepoints (Figure 5E and 5F), these protective effects were lost. Taken together, these studies in the larvae model demonstrate the therapeutic potential of the GNPs, which was not clearly evident from the initial in vitro MIC studies. In the initial treatment model data in 
Figure 4B where the GNP and free drug were similarly effective, it could be that the drug is rapidly released from the GNP to allow similar levels of exposure as the free drug. However, when considered with the latter findings showing the controlled release effect, this would suggest that the drug in its free form is rapidly excreted from the larvae, but this would require further analysis. Interestingly in humans, gentamicin has a short half-life (40 minutes in the lung) and is excreted rapidly through the kidneys [37], and therefore similar enhanced therapeutic effects could be achieved clinically.

3.4 GNPs can Abrogate Intracellular K. pneumoniae Infection

Next we examined the potential of the GNPs to be taken up by $K$. pneumoniae infected macrophages and to inactivate the viability of these intracellular pathogens. Recent research has clearly shown that macrophages can act as 'reservoirs' for intracellular bacteria in order to avoid clearance leading to chronic infection [22,38-40]. Based on this finding, a macrophage-Klebsiella co-culture model was employed to assess intracellular anti-bacterial activities of gentamicin-loaded nanoparticles in Klebsiella-infected macrophages [8]. As professional phagocytes, we reasoned that the GNPs would be passively targeted and engulfed by macrophages. Macrophages with GFP-labelled tagged K. pneumoniae (green) and RNPs (red), and sub-cellular localization examined after 3 hrs by confocal microscopy. The images in Figure 6A show that both the particles and the bacteria are internalized into the cells and that these are contained together with LAMP1-positive KCV which live Klebsiella prevents fusing with lysosomes as we have previously observed [8]. This co-localisation of the particles and bacteria would suggest that drug loaded particles would have access to the intracellular infection within the macrophages. Importantly, control experiments showed that at these concentrations the PLGA NPs elicited no obvious toxicity towards macrophage populations (Figure 6B). Next, we treated macrophages harboring the bacteria with the GNPs 
for $3 \mathrm{hrs,}$ and upon detergent lysis of the macrophages, bacterial colony forming units were quantified. This analysis clearly showed a significant reduction in CFUs upon treatment with the GNPs over controls in murine alveolar macrophage (MH-S) (Figure 6C). In order to examine a longer infection and treatment window, we used human monocytic THP1 cells, which are more tolerant toward intracellular $K$. pneumoniae (18 hrs). As before, GNP treatment effectively cleared the intracellular infection from these cells (Figure 6D).

3.5 GNPs can reduce inflammatory and pyroptotic caspase signatures in infected macrophages

We next examined caspase activities in order to more fully appreciate the effects of the GNPs treatment on the infected cells. The triggering of inflammasome activation by intracellular gram-negative bacteria infection has been reported previously [33,41], but particulates can also induce inflammatory responses and caspase activation [42]. Recent studies have shown that intracellular infection of macrophages can activate caspase-1, which can lead to a pyroptotic cell death [41,43-45]. In agreement we found that $4 \mathrm{hrs}$ infection of $K$. pneumoniae in $\mathrm{MH}-\mathrm{S}$ cells generated a marked increase in caspase 1 activity in cell lysates. Although treatment of non-infected macrophages with the GNPs also generated a small increase in caspase 1 activity, we encouragingly found that GNP treatment of the infected cells reduced caspase 1 activation (Figure 7A). Caspase 1 activity levels can also be monitored through incubation of cell with a membrane-permeable FAM-FLICA ${ }^{\circledR}$ caspase-1 probe and visualized by fluorescence microscopy. Studies performed using this probe confirmed that the GNPs were able to reduce caspase 1 activity levels in the infected MH-S cells (Figure 7B).

Finally we also examined the activation of caspase 3 . In order to detect activation of this pro-apoptotic executor caspase we prolonged the post-infection incubation time from 3 hours 
to 24 hours, detecting a marked increase in caspase 3 activity in infected cells. Crucially, once more we found that co-treatment of the infected cells with GNPs reduced caspase-3 activity to basal levels (Figure 7C).

\section{Conclusion}

We have demonstrated the effectiveness of a nanoparticle formulation strategy and generated anti-microbial effects towards $K$. pneumoniae in both in vitro cultures and in vivo models. These results support the utility of nano-antibiotic technology and our findings support the development of GNPs for the treatment of intracellular $K$. pneumoniae to combat infection and associated inflammation without compromising cellular viability. Although here we have focused on high drug loading in our particles, further investigation into the size, charge and other physiochemical properties of antibiotic-loaded particles may further enhance intracellular anti-microbial effects in the future.

\section{Funding Sources}

This work was funded in part through Biotechnology and Biological Sciences Research Council award BB/P006078/1. 


\section{References}

[1] Global Priority List of Antibiotic-Resistant Bacteria to Guide Research, Discovery and Development of New Antibiotics. http://www.who.int/medicines/publications/global-priority-list-antibiotic-resistant-bacteri a/en/

[2] A. Borer, L. Saidel-Odes, K. Riesenberg, S. Eskira, N. Peled, R. Nativ, et al., Attributable mortality rate for carbapenem-resistant Klebsiella pneumoniae bacteremia, Infect. Control. Hosp. Epidemiol. 30 (2015) 972-976. http $/ /$ dx.doi.org/10.1086/605922.

[3] S. Gürntke, C. Kohler, I. Steinmetz, Y. Pfeifer, C. Eller, P. Gastmeier, et al., Molecular epidemiology of extended-spectrum beta-lactamase (ESBL)-positive Klebsiella pneumoniae from bloodstream infections and risk factors for mortality, J. Infect. Chemother. 20 (2014) 817-9. http://dx.doi.org/10.1016/i.jiac.2014.08.012.

[4] I.A. Ginaw, Hospital acquired infections among patients admitted in the medical and surgical wards of a non-teaching secondary care hospital in northern india, J. Clin. Diagn. Res. 8 (2014) 81-3. http://dx.doi.org/10.7860/JCDR/2014/6673.4014.

[5] T. Ipekci, D. Seyman, H. Berk, O. Celik, Clinical and bacteriological efficacy of amikacin in the treatment of lower urinary tract infection caused by extended-spectrum beta-lactamase-producing Escherichia coli or Klebsiella pneumoniae, J. Infect. Chemother. 20 (2014) 762-7.http://dx.doi.org/10.1016/j.jiac.2014.08.007.

[6] F.J. Mpogoro, S.E. Mshana, M.M. Mirambo, B.R. Kidenya, B. Gumodoka, C. Imirzalioglu, Incidence and predictors of surgical site infections following caesarean sections at Bugando Medical Centre, Mwanza, Tanzania, Antimicrob Resist Infect Control. 3 (2014) 25-35. http://dx.doi.org/10.1186/2047-2994-3-25.

[7] R. Laxminarayan, A. Duse, C. Wattal, A.K.M. Zaidi, H.F.L. Wertheim, N. Sumpradit, et al., The Lancet Infectious Diseases Commission Antibiotic resistance--the need for global solutions, Lancet. Infect. Dis. 13 (2013) 1057-1098. http://dx.doi.org/10.1016/S1473-3099(13)70318-9.

[8] V.Cano, C. March, J.L. Insua, N. Aguiló, E. Llobet, D. Moranta, et al., Klebsiella pneumoniae survives within macrophages by avoiding delivery to lysosomes, Cell Microbiol. 17 (2015) 1537-1560. http://dx.doi.org/10.1111/cmi.12466. 
[9] M.K. Lacy, D.P. Nicolau, C.H. Nightingale, The pharmacodynamics of aminoglycosides, Clinical infectious diseases. 27 (1998) 23-27. http://dx.doi.org/10.1086/514620

[10] E.J. Begg, M.L. Barclay, Aminoglycosides-50 years on, Br. J. Clin. Pharmacol. 39 (1995) 597-603.

[11] R. Schiffelers, G. Storm, I. Bakker-Woudenberg, Liposome-encapsulated aminoglycosides in pre-clinical and clinical studies, J. Antimicrob. Chemother. 48 (2001) 333-344.

[12] A.M. Abraham, A. Walubo, The effect of surface charge on the disposition of liposome-encapsulated gentamicin to the rat liver, brain, lungs and kidneys after intraperitoneal administration, Int. J. Antimicrob. Agents. 25 (2005) 392-397. http://dx.doi.org/10.1016/j.ijantimicag.2005.01.018.

[13] M. Maurin, D. Raoult, Use of aminoglycosides in treatment of infections due to intracellular bacteria, Antimicrob. Agents. Chemother. 45 (2001) 2977-2986. http://dx.doi.org/10.1128/AAC.45.11.2977-2986.2001.

[14] B.K. Bains, M.K. Greene, L.M. McGirr, J. Dorman, S.N. Farrow, C.J. Scott, Encapsulation of the p38 MAPK inhibitor GSK 678361A in nanoparticles for inflammatory-based disease states, J. Interdiscip. Nanomed. 1 (2016): 85-92. http://dx.doi.org/10.1002/jin2.9

[15] Y.C. Huang, R.Y. Li, J.Y. Chen, J.K. Chen, Biphasic release of gentamicin from chitosan/fucoidan nanoparticles for pulmonary delivery, Carbohydr Polym. 15 (2016) 114-122. http://dx.doi.org/10.1016/j.carbpol.2015.11.072.

[16] E. Briones, C. Isabel Colino, J.M. Lanao, Delivery systems to increase the selectivity of antibiotics in phagocytic cells, J. Control. Release. 125 (2008) 210-227. http://dx.doi.org/10.1016/j.jconre1.2007.10.027.

[17] A. Ranjan, N. Pothayee, M.N. Seleem, S.M. Boyle, R. Kasimanickam, J.S. Riffle, et al, Nanomedicine for intracellular therapy, FEMS Microbiol Lett. 332 (2012) 1-9. http://dx.doi.org/10.1111/j.1574-6968.2012.02566.x.

[18] J.M. Xue, C.H. Tan, D. Lukito, Biodegradable polymer-silica xerogel composite microspheres for controlled release of gentamicin, J. Biomed. Mater. Res. 78B (2006) 417-422. http://dx.doi.org/10.1002/jbm.b.30503. 
[19] H. Zazo, C.I. Colino and J.M. Lanao, Current applications of nanoparticles in infectious diseases, J. Control. $\quad$ Release. $224 \quad$ (2016) 86-102. http://dx.doi.org/10.1016/j.jconre1.2016.01.008.

[20] Irma A.J.M. Bakker-Woudenberg, M.T.ten Kate, L.E.T. Stearne-Cullen and M.C. Woodle, Efficacy of Gentamicin or Ceftazidime Entrapped in Liposomes with Prolonged Blood Circulation and Enhanced Localization in Klebsiella pneumoniae-Infected Lung Tissue, J. Infect. Dis. 171 (1995) 938-947. https://doi.org/10.1093/infdis/171.4.938.

[21] J.R. Benson, P.E. Hare, O-phthalaldehyde: Fluorogenic detection of primary amines in the picomole range. Comparison with fluorescamine and ninhydrin, Proc. Natl. Acad. Sci. USA. 72 (1975) 619-622.

[22] L. Nguyen, J. Pieters, The Trojan horse: survival tactics of pathogenic mycobacteria in macrophages, Trends. Cell. Biol. $15 \quad$ (2005) 269-276. http://dx.doi.org/10.1016/j.tcb.2005.03.009.

[23] J. Deacon, S.M. Abdelghany, D.J. Quinn, D. Schmid, J. Megaw, R.F. Donnelly, C.C. Taggart, C.J. Scott, Antimicrobial efficacy of tobramycin polymeric nanoparticles for Pseudomonas aeruginosa infections in cystic fibrosis: Formulation, characterisation and functionalisation with dornase alfa (DNase), J. Control. Release. 198 (2015) 55-61. http://dx.doi.org/10.1016/j.jconre1.2014.11.022.

[24] S.M. Abdelghany, D.J Quinn, R.J. Ingram, B.F. Gilmore, R.F. Donnelly, C.C. Taggart, C.J. Scott, Gentamicin-loaded nanoparticles show improved antimicrobial effects towards Pseudomonas aeruginosa infection, Int. J. Nanomedicine. 7 (2012) 4053-4063. http://dx.doi.org/10.2147/IJN.S34341.

[25] C. Lecaroz, M.J. Blanco-Prieto, M.A. Burrell, C. Gamazo. Intracellular killing of Brucella melitensis in human macrophages with microsphere-encapsulated gentamicin, J. Antimicrob. Chemother. 58 (2006) 549-556. http://dx.doi.org/10.1093/jac/dk1257.

[26] K. Seifi, H. Kazemian, H. Heidari, F. Rezagholizadeh, Y. Saee, F. Shirvani, and H. Houri, Evaluation of Biofilm Formation Among Klebsiella pneumoniae Isolates and Molecular Characterization by ERIC-PCR, Jundishapur. J. Microbiol. 9(2016) e30682. http://dx.doi.org/10.5812/jjm.30682. 
[27] C. Vuotto, F. Longo, M.P. Balice, G. Donelli, and P.E. Varaldo, Antibiotic Resistance Related to Biofilm Formation in Klebsiella pneumoniae, Pathogens. 3 (2014) 743-758. http://dx.doi.org/10.3390/pathogens3030743.

[28] M.D. Macia, E. Rojo-Molinero, A. Oliver, Antimicrobial susceptibility testing in biofilm-growing bacteria, Clin. Microbiol. Infect. 20 (2014) 981-990. http://dx.doi.org/10.1111/1469-0691.12651.

[29] S. Singla, K. Harjai and S.Chhibber, Susceptibility of different phases of biofilm of Klebsiella pneumoniae to three different antibiotics, J. Antibiot. 66 (2013) 61-66. http://dx.doi.org/10.1038/ja.2012.101.

[30] W.S. Cheow, M.W. Chang and K. Hadinoto, Antibacterial Efficacy of Inhalable Levofloxacin-Loaded Polymeric Nanoparticles Against E. coli Biofilm Cells: The Effect of Antibiotic Release Profile, Pharm. Res. 27 (2010) 1597-1609. http://dx.doi.org/10.1007/s11095-010-0142-6.

[31] L. Hill, N. Veli, P.J. Coote, Evaluation of Galleria mellonella larvae for measuring the efficacy and pharmacokinetics of antibiotic therapies against Pseudomonas aeruginosa infection, Int. J. Antimicrob. Agents. 43 (2014) 254-261. http://dx.doi.org/10.1016/j.ijantimicag.2013.11.001.

[32] G. Jander, L.G. Rahme, F.M. Ausubel, Positive correlation between virulence of Pseudomonas Aeruginosa mutants in mice and insects, J. Bacteriol. 182 (2000) 3843-3845. http://dx.doi.org/10.1128/JB.182.13.3843-3845.2000.

[33] R.J. Thomas, K.A. Hamblin, S.J. Armstrong, C.M. Müller, M. Bokori-Brown, S. Goldman, et al., Galleria mellonella as a model system to test the pharmacokinetics and efficacy of antibiotics against Burkholderia Pseudomallei, Int. J. Antimicrob. Agents. 41 (2013) 330-336. http://dx.doi.org/10.1016/j.ijantimicag.2012.12.009.

[34] J.L. Insua, E. Llobet, D. Moranta, C. Perez-Gutierrez, A. Tomas, J. Garmendia, et al., Modeling Klebsiella pneumoniae Pathogenesis by Infection of the Wax Moth Galleria mellonella, Infect. Immun. 81 (2013) 3552-3565. http://dx.doi.org/10.1128/IAI.00391-13.

[35] M.F. Pereira, C.C Rossi, M.V. de Queiroz, G.F. Martins, C. Isaac, J.T. Bossé, Y. Li Y, B.W. Wren BW, V.S. Terra, J. Cuccui, P.R. Langford, D.M. Bazzolli, Galleria mellonella is an effective model to study Actinobacillus pleuropneumoniae infection, Microbiology. 161 (2015) 387-400. http//dx.doi.org/10.1099/mic.0.083923-0. 
[36] M. Lu, C. Yu, X. Cui, J. Shi, L. Yuan, S. Sun. Gentamicin synergises with azoles against drug-resistant Candida albicans, Int. J. Antimicrob. Agents. 51 (2018) 107-114. http://dx.doi.org/10.1016/j.ijantimicag.2017.09.012.

[37] J.J. Schentag, W.J. Jusko, Renal clearance and tissue accumulation of gentamicin, Clin. Pharmacol. Ther. 22 (1977) 364-370. https://doi.org/10.1002/cpt1977223364.

[38] P.J. Liu, Y.S. Chen, H.H. Lin, W.F. Ni, T.H. Hsieh, H.T. Chen, et al., Induction of Mouse Melioidosis with Meningitis by CD11b+ Phagocytic Cells Harboring Intracellular B. pseudomallei as a Trojan Horse, PLoS. Negl. Trop. Dis. 7 (2013) 2363-2376. http://dx.doi.org/10.1371/journal.pntd.0002363.

[39] N.C.W. Tan, A. Foreman, C. Jardeleza, R. Douglas, S. Vreugde, P.J. Larvaeald, Intracellu lar Staphylococcus aureus: the Trojan horse of recalcitrant chronic rhinosinusitis? Int. Forum. Allergy. Rhinol. 3 (2013) 261-266. http://dx.doi.org/10.1002/alr.21154.

[40] C. Lecaroz, C. Gamazo, M.J. Renedo, M.J. Blanco-Prieto, Biodegradable micro- and nanoparticles as long-term delivery vehicles for gentamicin, J. Microencapsul. 23 (2006) 782-792. http://dx.doi.org/10.1080/02652040600946886.

[41] Y. Koizumi, C. Toma, N. Higa, T. Nohara, N. Nakasone, T. Suzuki, Inflammasome activation via intracellular NLRs triggered by bacterial infection, Cell. Microbiol. 14 (2012):149-154. http://dx.doi.org/10.1111/j.1462-5822.2011.01707.x.

[42] C.S. Hughes, L.M. Colhoun, B.K. Bains, J.D. Kilgour, R.E. Burden, J.F. Burrows, E.C. Lavelle, B.F. Gilmore, C.J. Scott, Extracellular cathepsin S and intracellular caspase 1 activation are surrogate biomarkers of particulate-induced lysosomal disruption in

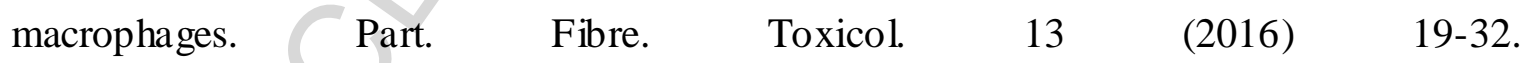
https://doi.org/10.1186/s12989-016-0129-5.

[43] E.A. Miao, I.A. Leaf, P.M. Treuting, D.P. Mao, M. Dors, A. Sarkar, S.E. Warren, M.D. Wewers, A. Aderem, Caspase-1-induced pyroptosis is an innate immune effector mechanism against intracellular bacteria, Nat. Immunol. 11 (2010):1136-1142. http://dx.doi.org/10.1038/ni.1960.

[44] S.B. Willingham, I.C. Allen, D.T. Bergstralh, W.J. Brickey, M.T. Huang, D.J. Taxman, J.A. Duncan, J.P. Ting, NLRP3 (NALP3, Cryopyrin) facilitates in vivo caspase-1 activation, necrosis, and HMGB1 release via inflammasome-dependent and -independent 
$\begin{array}{lllll}\text { pathways, } & \text { J. } & \text { Immunol. } & 183 & \text { (2009): }\end{array}$

http://dx.doi.org/10.4049/jimmuno1.0900138.

[45] I. Jorgensen, M. Rayamajhi, E.A. Miao, Programmed cell death as a defence against infection, Nat. Rev. Immunol. 17 (2017):151-164. http://dx.doi.org/10.1038/nri.2016.147. 
Figure 1. Schematic overview of the adopted formulation process for the preparation of gentamicin-loaded PLGA nanoparticles (GNPs) using a water-in-oil-in-water (W/O/W) formulation

Figure 2 A. Physical Analysis of GNPs by Dynamic Light Scattering (DLS); B. Scanning Electron Microscope (SEM) Image of BNPs and GNPs.

Figure 3 A. Planktonic MIC determination against K. pneumoniae; B. the Release study in PBS buffer (pH 5.5 and 7.4) at $37{ }^{\circ} \mathrm{C}$ over $120 \mathrm{hrs}$ (Mean $\pm \mathrm{SD}, \mathrm{n}=3$ ); C. Biofilm-derived planktonic MIC determination (Mean $\pm S D, n=3$ ); $D$. the MBEC determination against $24 \mathrm{hrs}$ pre-established $K$. pneumoniae biofilm (Mean $\pm \mathrm{SD}$, $\mathrm{n}=3$ ). Kp, K. pneumoniae; GNP, gentamicin-loaded nanoparticle; BNP, blank nanoparticle; FG, free gentamicin.

Figure $4 \mathrm{~A}$. Virulence screen of $K$. pneumoniae $\left(\mathrm{LD}_{50}\right)$; $\mathrm{B}$. The treatments against lethal $K$. pneumoniae post-infection. (statistical significance analysed between all groups [n=10 per group] using log-rank [Mantel-Cox] test, ${ }^{* * * *} \mathrm{P}<0.0001$ ); C. Hemocytes quantification after $K$. pneumoniae infection in Galleria Larvae. D. Bacterial replication at $8 \mathrm{hrs}$ after $K$. pneumoniae infection in Galleria Larvae. (statistical significance analysed between all groups [ $\mathrm{n}=10$ per group] using one-way ANOVA analysis in comparison to the untreated control, $\left.{ }^{* * *} \mathrm{P}<0.0001\right)$.

Figure 5. The Pre-Treatment Study of GNPs against $K$. pneumoniae in vivo. Treatments (NPs $40 \mu \mathrm{g} /$ Larvae [loaded gentamicin $3.6 \mu \mathrm{g} / \mathrm{Larvae}$ ], Free Gentamicin $3.6 \mu \mathrm{g} /$ Larvae and PBS $10 \mu /$ Larvae) were injected into Larvae (A) 0, (B) 24, (C) 48, (D) 72, (E) 96 and (F) 120 hours prior to the LD 50 (104 CFU/Larvae) and survival monitored up to 120 hours post-infection (Statistical significance analysed between all groups [ $\mathrm{n}=10$ per group] using log-rank [Mantel-Cox] test, ${ }^{*} \mathrm{P}<0.05,{ }^{*} \mathrm{P}<0.001$, $* * * * \mathrm{P}<0.0001)$.

Figure 6 A. The sub-cellular localisation of NPs and K. pneumoniae in an infected macrophage; B. Cell viability in NPs treated MH-S macrophages; C\&D. Intracellular bacteria quantification after NPs treatments in a MH-S (C)/THP1 (D) Macrophages \& 
K. pneumoniae co-culture model (statistical significance analysed between treatments and free gentamicin groups using one-way ANOVA, ${ }^{*} \mathrm{P}<0.05$ ).

Figure 7 A. Fluorometric Caspase-1 activity assay; B. The Caspase-1 activity in treated $\mathrm{MH}-\mathrm{S}$ cells through confocal microscopy ( $i$ Unstimulated MH-S cells; ifGNPs treated cells; iii- $K$. pneumoniae infected cells; iv-GNPs treated $K$. pneumoniae infected cells, scale bar $=10 \mu \mathrm{m}) ; C$. Fluorometric Caspase- $3 / 7$ activity assay (Statistical significance analysed between all groups using one-way ANOVA, $\left.{ }^{* *} \mathrm{P}<0.01,{ }^{* * *} \mathrm{P}<0.001,{ }^{* * *} \mathrm{P}<0.0001\right)$.

Supplementary Figure 1. The optimisation strategies for gentamicin-loaded nanoparticles formulation: the impacts of polymer concentrations, surfactant concentration ( $\mathrm{min} / \mathrm{max}$ PLGA amount), different aqueous phase in 1 st emulsion step and external aqueous $\mathrm{pH}$ on Entrapment Efficiency\% ( $A$ to $E$ ) and size ( $F$ to $J$ ). Statistical significance analysed in comparisons with mosaic group using one-way ANOVA, $\left.{ }^{*} P<0.05,{ }^{* *} P<0.01,{ }^{* * *} P<0.001,{ }^{* * * *} P<0.0001\right)$.

Supplementary Figure 2. Localization of K. pneumoniae and NPs in Galleria Larvae (arrows in each channels were scatted hemocytes [Blue], GFP-tagged $K$. pneumoniae [Green] and Rhodamine NPs [Red], respectively. Scale bar $=8 \mu \mathrm{m})$.

Supplementary Figure 3. Histopathological analysis of NPs treated K. pneumoniae infection in Galleria Larvae using Haemotoxylin and Eosin staining (P.I. = Post Infection; Black arrows were melanization positions; Blue arrows were hemocytes; Scale bar $=10 \mu \mathrm{m})$.

Supplementary Table 1. MBC values for GNP and free gentamicin over 5 days. 


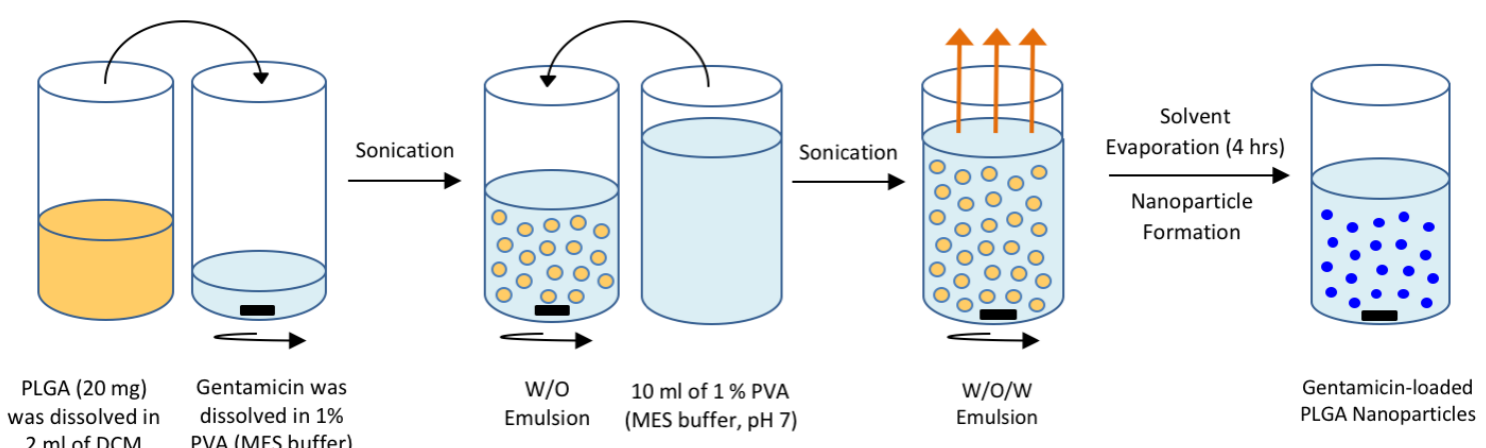

Fig: 1 
A

Size Distribution by Intensity

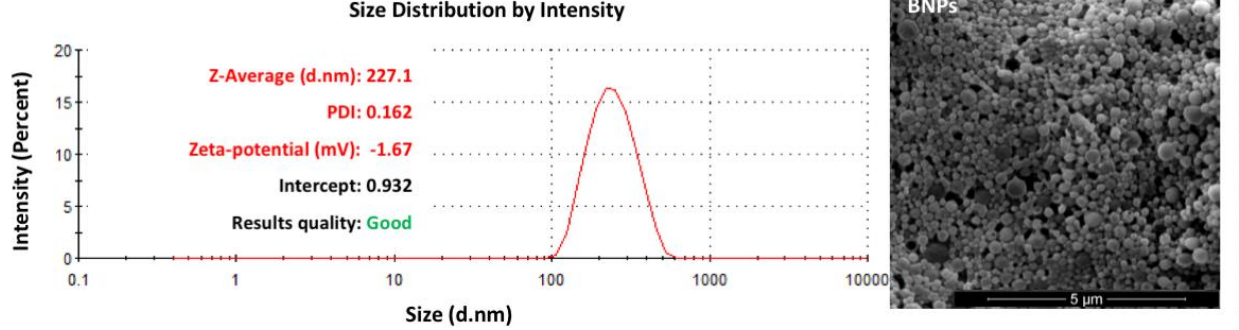

Fig: 2
B

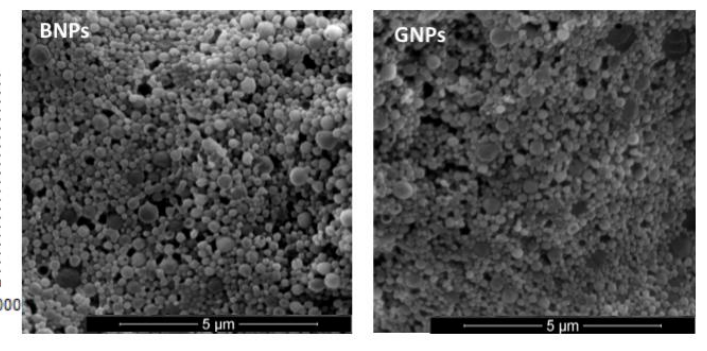


A

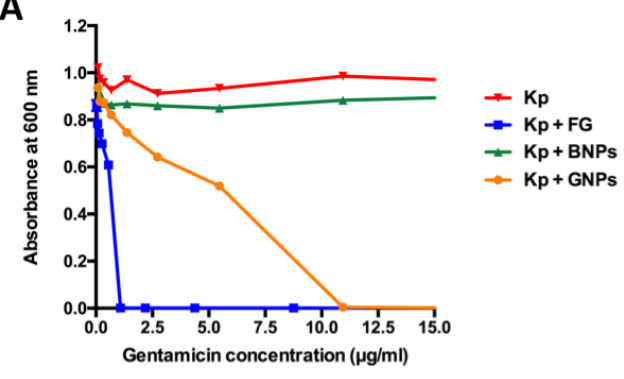

C

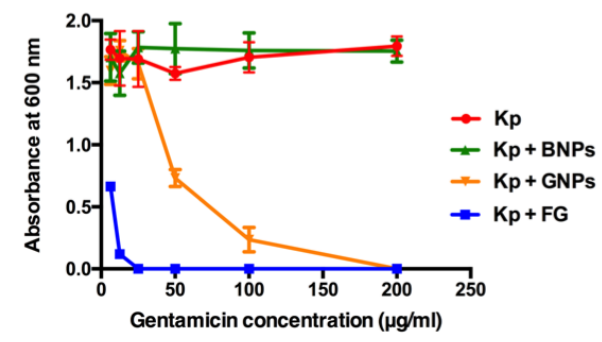

B

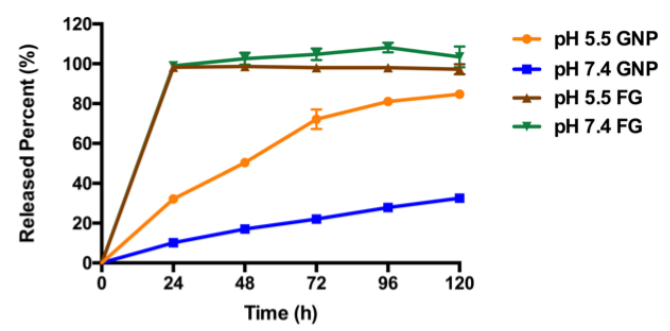

D

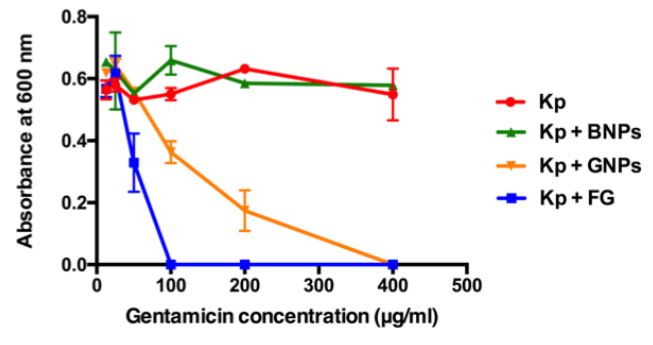

Fig: 3 
A

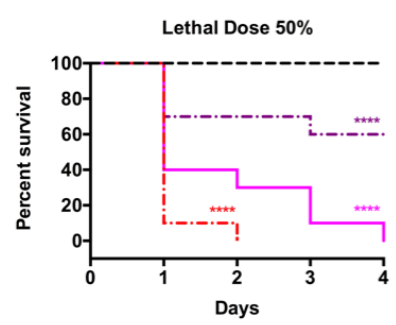

-- PBS

$-10^{4}$ CFU/Larvae

-.. $10^{5}$ CFU/Larvae -.. $10^{3}$ CFU/Lanae

C

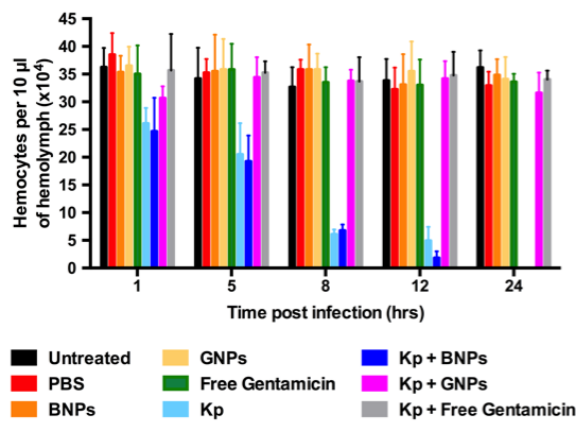

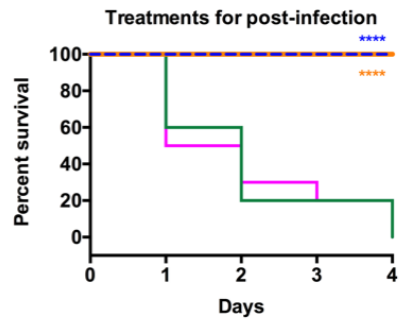

$\begin{array}{ll}\text {-- Free Gentamicin } & - \text { BNPs } \\ \text { - GNPs } & \sim \text { PBS }\end{array}$

D

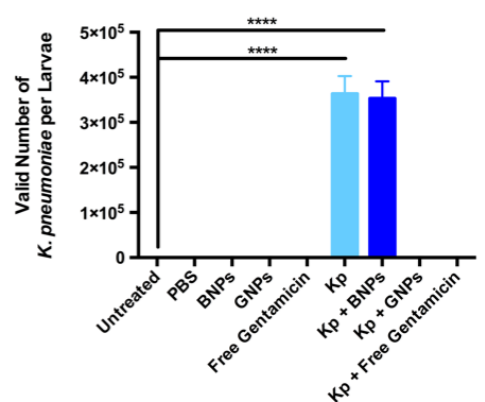

Fig: 4 
A

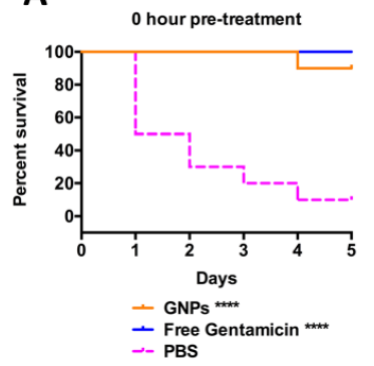

D

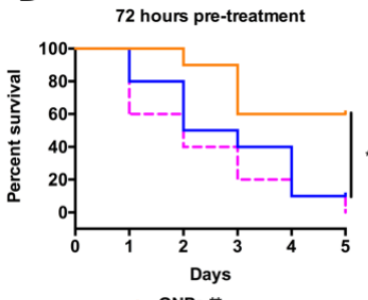

- GNPs *

I- Free Gentamicin "
B

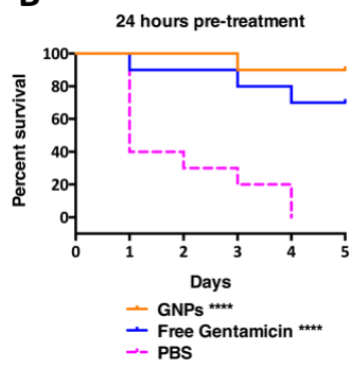

E

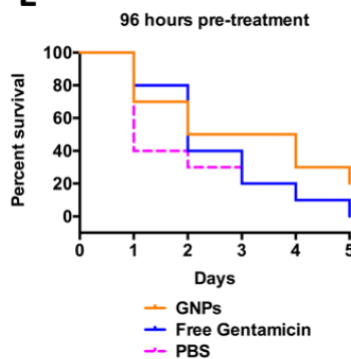

C

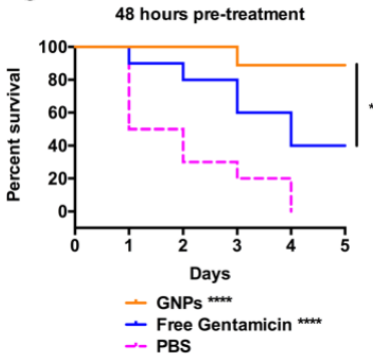

F

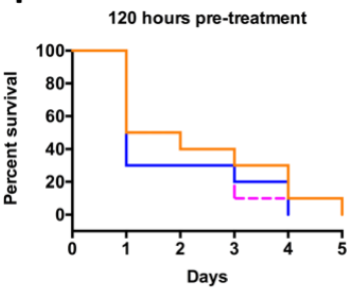

- GNPs

- Free Gentamicin

Fig: 5 
A

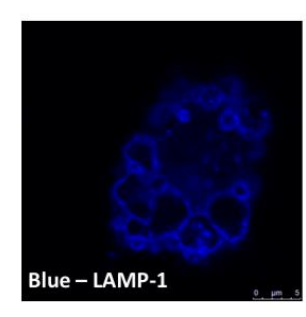

B

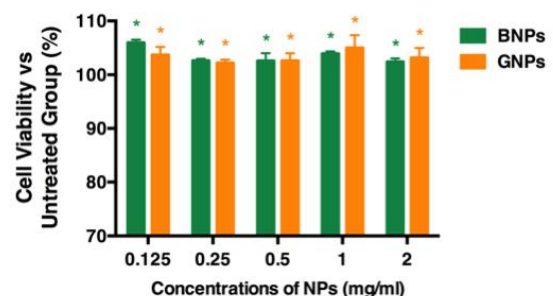

Fig: 6
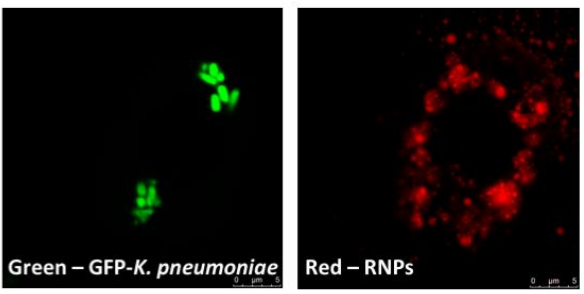

C

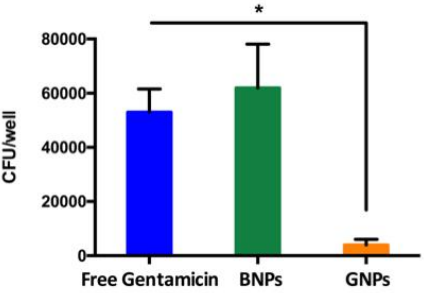

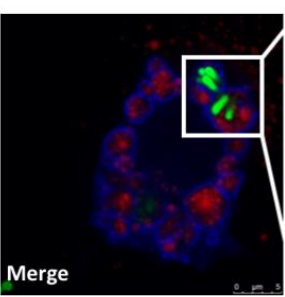

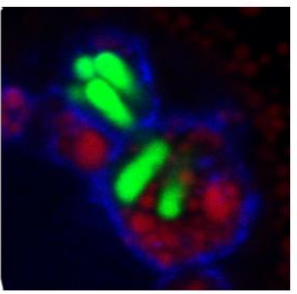

D

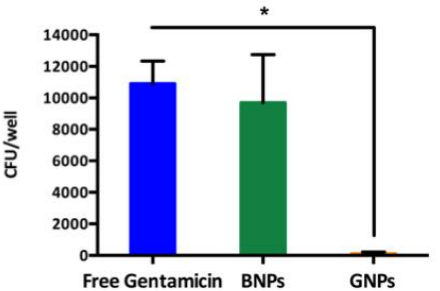


A

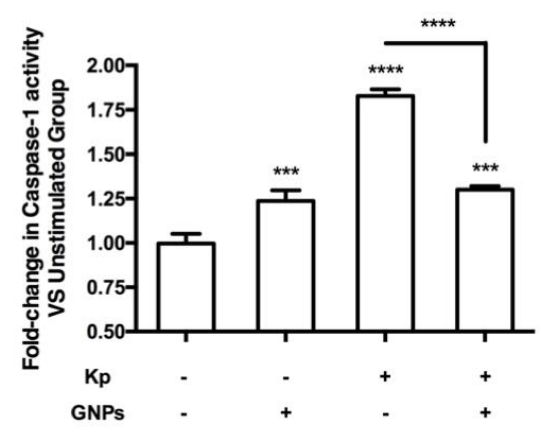

B

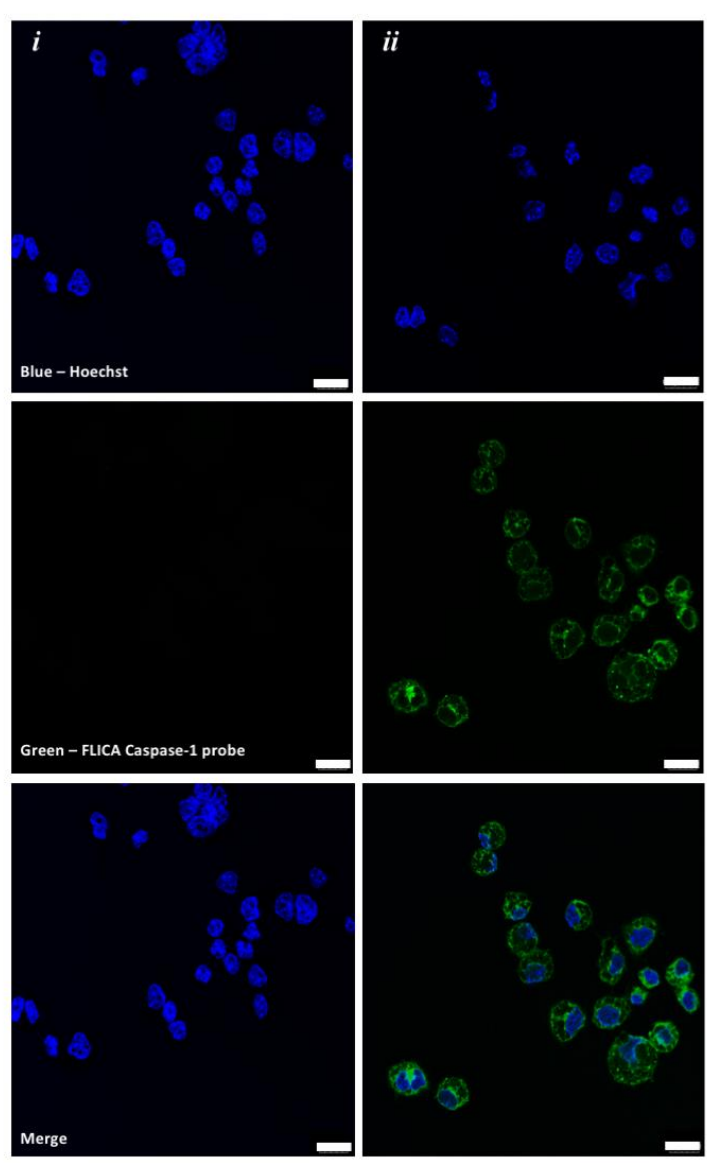

C

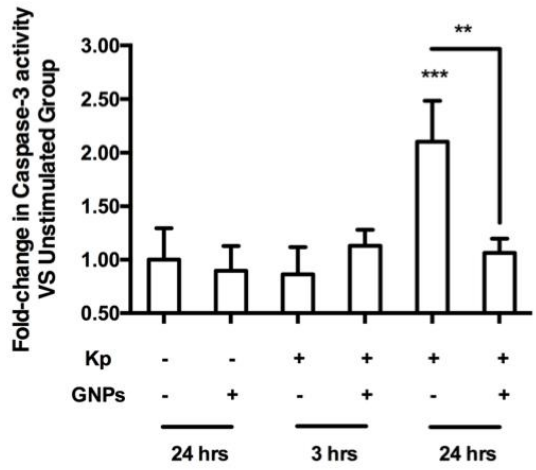

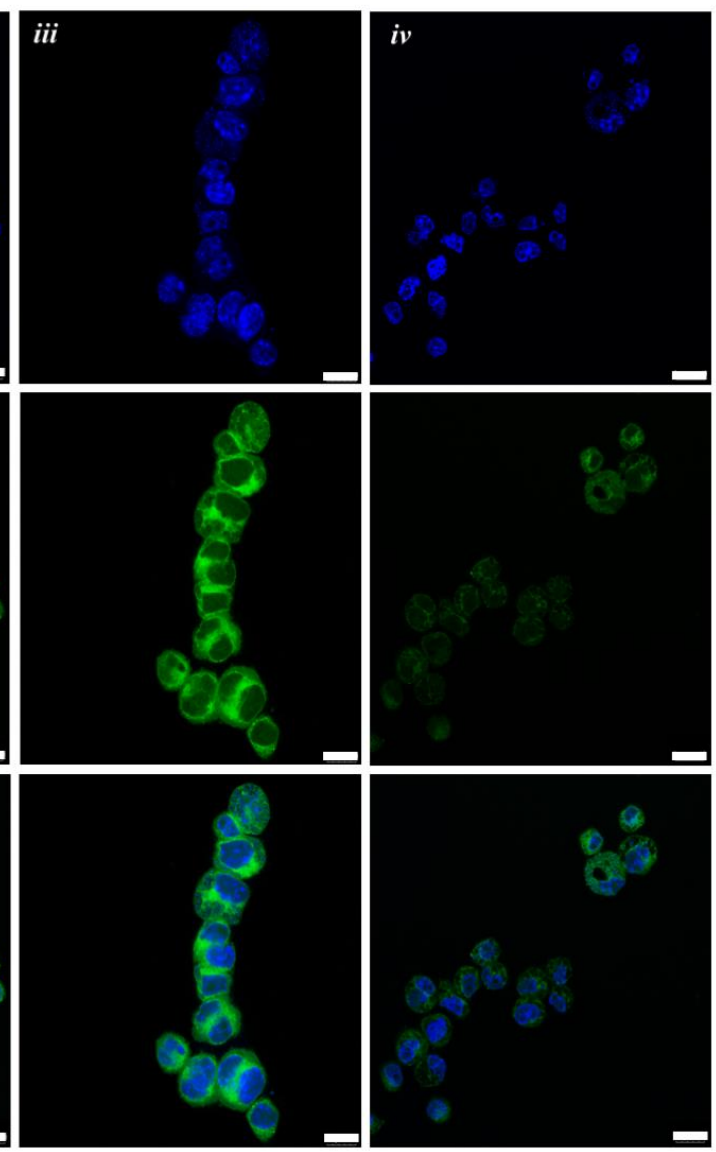

Fig: 7 


\section{Graphical abstract}
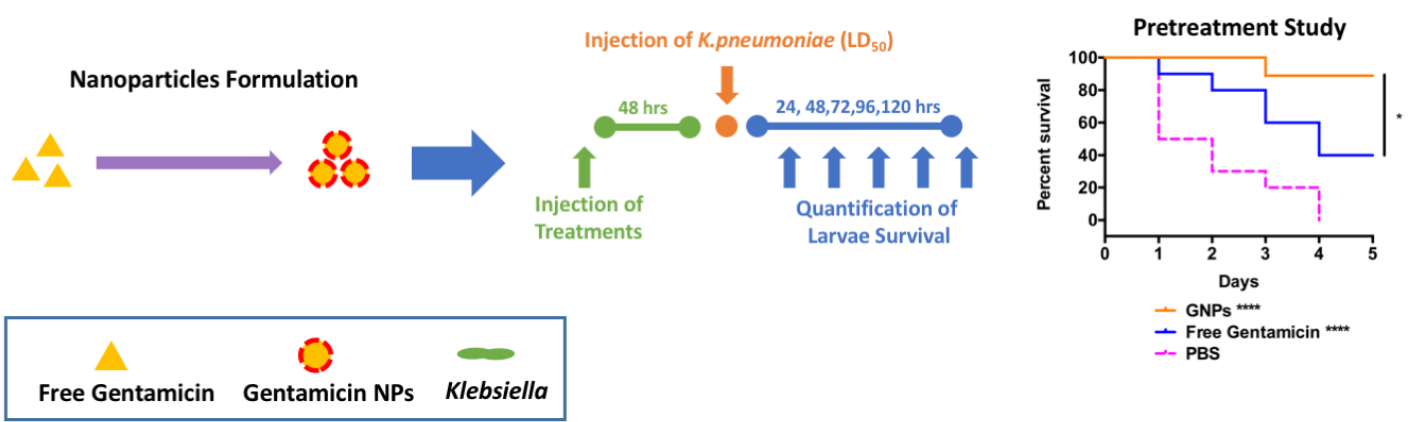

- GNPs

I GNPS

Free Gentamicin Gentamicin NPs Klebsiella
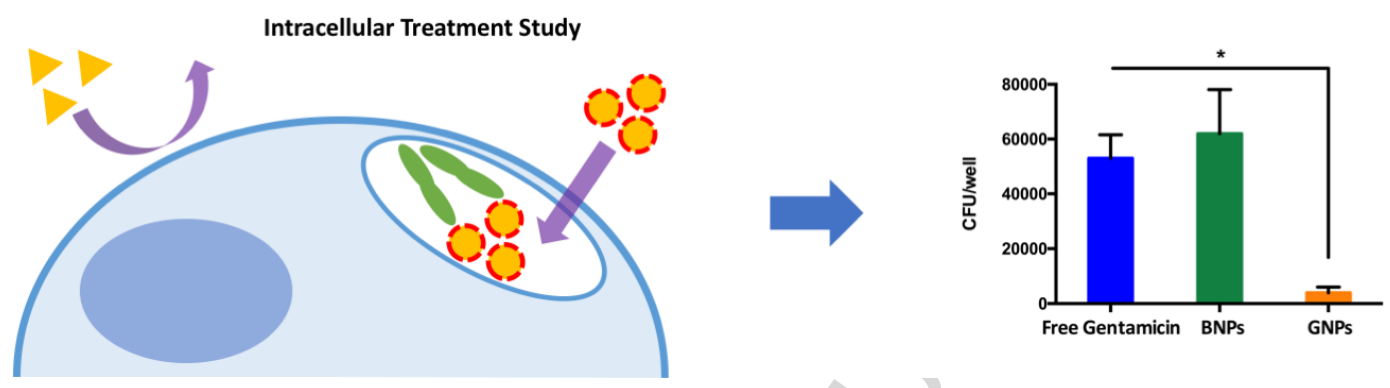